\title{
The Trends of Japanese Students' Participation in Study Abroad Programmes
}

\author{
Mari Katori \\ Aomori Public University, Aomori, Japan
}

\begin{abstract}
This article examines the trends in Japanese students who participate in study abroad programmes ("mobile students"). Features of recent Japanese mobile students are discussed, and case studies of 23 Japanese university students who have finished short-term study abroad programmes are examined to determine their awareness of, and any changes in, soft-skills, attitudes, and so on. A semi-structured interview method was adopted for the case study interviews, and G-TELP (General Test of English Language Proficiency) was used as a pre- and post-test to evaluate "hard skills". Although these hard skills showed no statistically significant improvements, interviews indicate changes in awareness and soft skills. Finally, a suggestion is made regarding how to improve and offer more effective short-term programmes for Japanese mobile students.
\end{abstract}

Keywords: mobile student, short-term study abroad programme, soft skills

\section{Introduction}

\section{Background of Japanese Mobile Students}

"Studying abroad" has been an important part of education in Japan for several centuries. Japan first sent official mobile students to China in the 6th century. In those days, the main purpose was to absorb new technologies, laws, or religious teachings, and only priests or nuns could take part in those missions. For example, "Envoys to Sui Dynasty China" is a very famous mission from that period. From the 6th century to the 14th century, Japanese students' main destination was China. This changed over time, until in the 19th century, soon after ending isolationism, Japan sent 16 people to the Netherlands to absorb modern technologies and cultures. From the end of the 19th through to the beginning of the 20th century, Germany was the major destination for Japanese mobile students. Since the 1940s, the USA has been the most popular destination. Yet, all through that time, the general pattern for studying abroad was a carefully-selected handful of people on a government-controlled programme spending a set duration abroad, where the stated goals were gaining scientific, technological, and cultural information to be brought back to help develop Japan. These select few returned and became heads of industry and founders of new organizations, colleges, and faculties.

Not only the destinations, but also the duration of study abroad has changed over time. From the 19th century through to the 1940s, average duration shortened gradually from five years to six months. This shortening duration reflects a gradual change in the purpose of studying abroad. Until the 1940s, the main

Mari Katori, professor, Management and Economics Department, Aomori Public University. 
purpose was one-way absorption of information — called "direct current type" study abroad by Gondo (1991), and "dispatch type" or "first generation style" by Kaneko (2000). However, according to a report by The Central Council for Education in 1956, study abroad was defined as "a part of promotion of international exchange matters regarding education, study and culture", indicating a shift from one-sided absorption of foreign cultures to two-way "exchange" (see also Tsuji, 2010, p. 4). In the 21st century, according to a report by Benesse Educational Research and Development Institute (2012), the main purposes of Japanese mobile students included "language learning", "international exchange experiences", or "international internship". Kaneko (2000) likewise suggests that while Japanese sojourners several decades ago focused almost exclusively on gaining some expertise or proficiency, recent sojourners have more diverse goals.

More recently, with travel easier and special visas no longer required for short-term study in some countries, study trips are both far more common and usually much shorter: According to a report by the Ministry of Education, Culture, Sports, Science and Technology in Japan (MEXT) in 2015, 97\% of the 69,869 Japanese studying abroad were on courses of less than one year in 2013, with the number seeking short-term study abroad placements in overseas universities increasing in recent years. In this article, I call study abroad programmes of less than one year "short-term" and one year or more programmes "long-term".

With Japan modernised, and a great deal of scientific, technological, and cultural information now available freely on the Internet, government and industry now sponsor study abroad for different reasons. Additionally, these shorter trips appear to no longer be primarily directed by government, but rather by universities and individuals. For universities, study abroad programmes are a way of attracting students in a time of decreasing rolls (as the population of Japan ages), and agreements with prestigious or attractive overseas institutions feature prominently in advertisements and promotional material.

\section{The Purpose of This Study}

Other research to date has examined the impact of short-term study placements on language skills (Kimura 2011; Nishikawa 2013), but research into what individuals need or want from such programmes is surprisingly hard to find. So, against this background of changing purposes and expectations for study abroad, the central aim of this study is to examine the trends of Japanese mobile students with a view to making sure that study abroad programmes meet the expectations of students effectively.

\section{Method}

\section{Participants and Programmes}

Twenty-three Japanese university students studying at the same university located in the northern part of Japan (Tohoku district), took part in this research. Each student belongs to one of three different departments (management, economics, and regional studies), none of them majoring in English. All students participated in a university-provided short-term study abroad programme between 2010 and 2015: 15 students went to the United States (Boston) for one or three months; 6 went to New Zealand (Waikato) for three weeks; and 2 went to the UK (Stirling) for one month. See Table 1 for details of the four programmes. 
Table 1

Details of the Four Study Abroad Programmes

\begin{tabular}{llll}
\hline Destination & Duration & Study hours (per week) & Accommodation \\
\hline Boston (USA) & 3 months & 25 & dormitory \\
Boston (USA) & 4 weeks & 20 & apartment \\
Waikato (NZ) & 3 weeks & 23 & home stay \\
dormitory \\
Stirling (UK)
\end{tabular}

\section{Measuring Hard Skills}

Fifteen of the 23 subjects have taken the G-TELP (General Test of English Language Proficiency) test before and after their study abroad period to check for any change in "hard-skills". The G-TELP is a reliable English proficiency test produced by the ITSC (International Testing Service Center) and has five levels (from one to five). The Level 3 test (for junior college or first- and second-year college students) was adopted for this study. The test contains three parts, namely, grammar, listening, and reading and vocabulary. Finally, their preand post-test results were analyzed by $t$-test.

\section{Measuring Soft Skills}

A semi-structural interview was used to check for changes in soft-skills and attitudes. The questions were developed with reference to Edwards (2009), and emailed to interviewees a few days in advance. Therefore interviewees could prepare rough answers in advance. Each interview was conducted individually and took about 45 to 60 minutes. Finally, interviewees' answers were analyzed to reveal changes in awareness and soft-skills.

\section{Findings}

\section{Japanese Mobile Students: The Present Situation}

Number of Japanese mobile students by year. Figure 1 shows the number of Japanese mobile students by year. The number increased significantly from the 1980s to the middle of the 2000s. However, in the last 12 years, the number has decreased gradually.

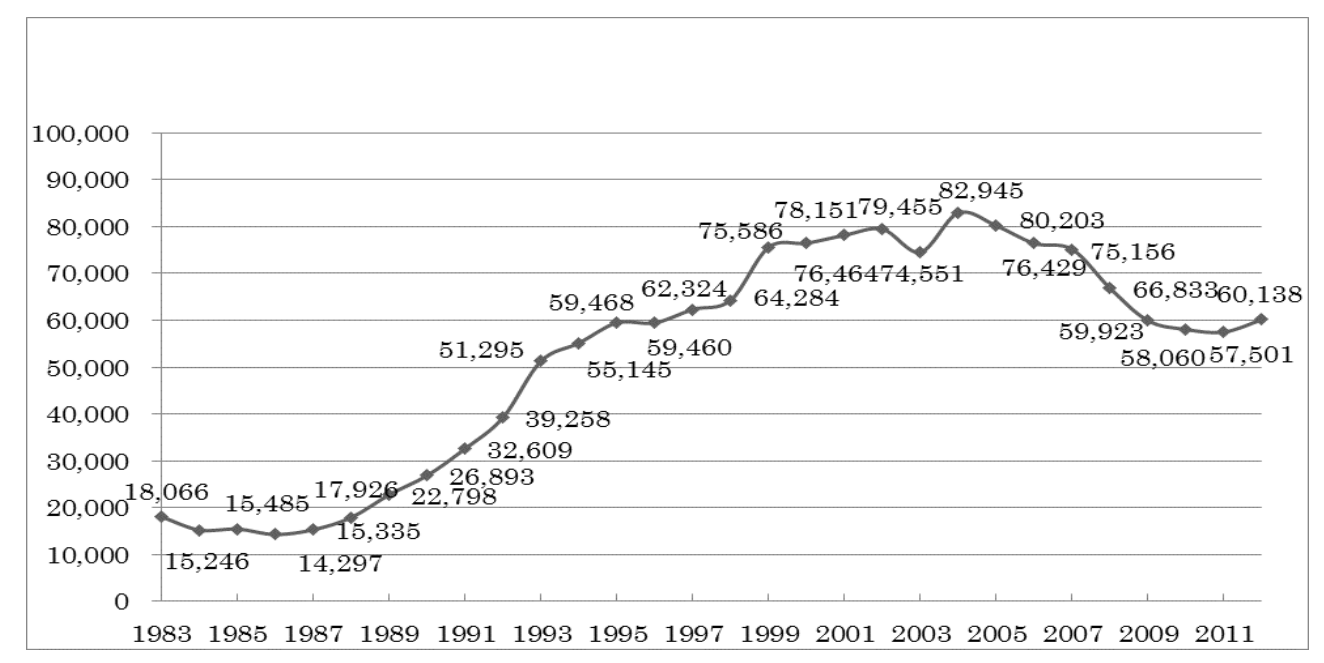

Figure 1. The number of Japanese mobile students by year by MEXT (2015). 
In the 1980s, the Ministry of Education, Culture, Sports, Science and Technology in Japan (MEXT) promoted international exchange programs. In addition, at that time, Japan was experiencing a business boom, income levels were increasing, and the affordability of study abroad grew. Those factors are presumed to be the main reasons for the increase in the 1980s. Also, some host countries were particularly active in welcoming foreign students during this period. For example, UK educational institutions were suffering financially in the 1980s under the Thatcher administration, and the UK adopted an "open-door policy" for mobile students in order to raise tuition revenues. Many US universities also hit financial difficulties during the same period, and one countermeasure involved establishing branch campuses in foreign countries such as Japan. Later, in the 1990s, some US universities launched new distance courses through the Internet.

However, over the last decade, the number of Japanese mobile students has decreased gradually. The major factor in this decrease appears to be that from the 1990s, Japan entered a long period of recession and (as economists say) "lost two decades", making study abroad increasingly unaffordable for students and families. Because of the recession, the domestic job market entered what was called "the ice age for job hunting", and students spent more and more time on job hunting and important events like job fairs, and less and less time on other activities, including study abroad. The general view in Japan is that young people at this time developed "risk avoidant" tendencies, favouring stability and trying to avoid changes. Only the final line segment in Figure 1 shows a slight recovery, with numbers climbing slightly in 2013 and 2014. Now, Japan is actively promoting "Tobitate Ryugaku Japan" ("leap for tomorrow!"), a study abroad campaign introduced in 2014, when 70,000 university students went abroad, intended to double that number of Japanese mobile students going overseas each year by 2020. So, the number of Japanese mobile students is expected to continue to increase at least until 2020.

Recent study abroad durations. Figure 2 shows figures from the Japan Student Services Organization (JASSO) on the duration of study abroad episodes by Japanese students in the 2013 and 2014 Japanese academic years.

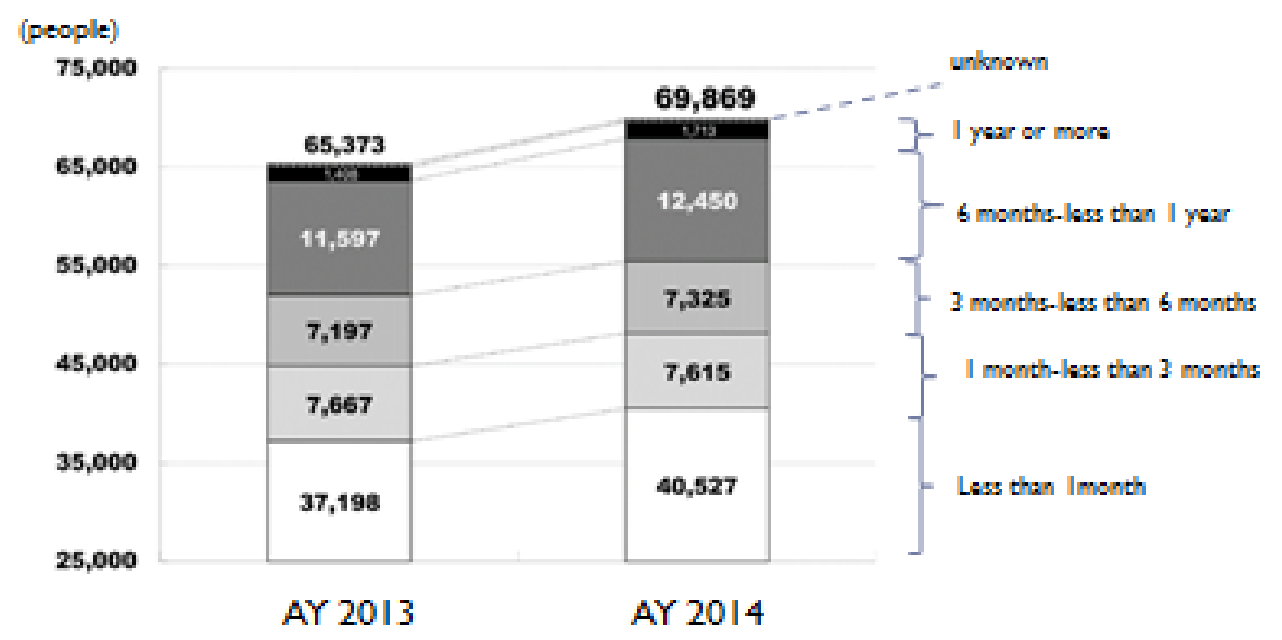

Figure 2. The duration of studying abroad by Japanese students (from MEXT 2015).

In $2014,97.2 \%$ of Japanese students who studied abroad went on short-term study abroad programmes, and only $2.5 \%$ of students stayed overseas for a year or more. 
Recent study abroad destinations. Table 2 shows the JASSO figures for recent destinations of Japanese mobile students. The USA is the most popular destination, but $22 \%$ of students visited a country not amongst the 10 most popular destinations, suggesting a diverse set of destinations. Historically, the main destinations were the economic or cultural powerhouses of the time, but the diversity of recent destinations is presumably a reflection of not only an increasingly multi-polar world (study abroad destinations for students from other countries show a similar diversification: see for example Wit, Ferencz, \& Rumbley, 2014), but also a wider range of student goals.

Table 2

Recent Destinations (from MEXT 2015)

\begin{tabular}{llcc}
\hline & Country/Region & Number & Previous year (AY 2012) \\
\hline 1 & USA & 16,794 & $(15,422)$ \\
2 & Canada & 6,614 & $(6,333)$ \\
3 & UK & 6,519 & $(5,614)$ \\
4 & Australia & 6,392 & $(5,768)$ \\
5 & Korea & 5,211 & $(5,542)$ \\
6 & China & 4,022 & $(5,796)$ \\
7 & Germany & 2,408 & $(2,495)$ \\
8 & France & 2,309 & $(2,290)$ \\
9 & Thailand & 2,249 & $(1,909)$ \\
10 & Taiwan & 2,080 & $(1,680)$ \\
11 & Others & 15,271 & $(12,497)$ \\
& Total & 69,869 & $(65,373)$ \\
\hline
\end{tabular}

\section{Case Studies: Changes in Japanese Mobile Students' Skills}

Hard skills. Table 3 shows the G-TELP results for the 15 students in the study who have already sat the test as a pre- and post-test.

Table 3

The Result of G-TELP (Pre- and Post-test)

\begin{tabular}{lll}
\hline Subject & Pre & Post \\
\hline A & 135 & 210 \\
B & 196 & 184 \\
C & 124 & 130 \\
D & 219 & 240 \\
E & 206 & 151 \\
F & 198 & 207 \\
G & 207 & 173 \\
H & 128 & 138 \\
I & 180 & 140 \\
J & 190 & 129 \\
K & 124 & 172 \\
L & 211 & 211 \\
M & 215 & 219 \\
N & 163 & 190 \\
O & 179 & 210 \\
Average & 178.33 & 180.27 \\
\hline
\end{tabular}


A one-tailed $t$-test on the hypothesis that scores have improved yields a $p$-value of 0.422681 , so the result is not significant at $p<0.05$.

The remaining eight subjects are yet to sit the post-test, and the sample size is very small, but we can tentatively conclude that short-term study abroad trips (these 15 students studied abroad for a mean period of 4.8 weeks) do not significantly improve English proficiency.

Soft skills. Figures 3 to 8 below illustrate the interview results. Note that as the interviews were semi-structured, and continued for 45-60 minutes, these figures show only a summary of the main themes that emerged in the (often long and varied) replies.

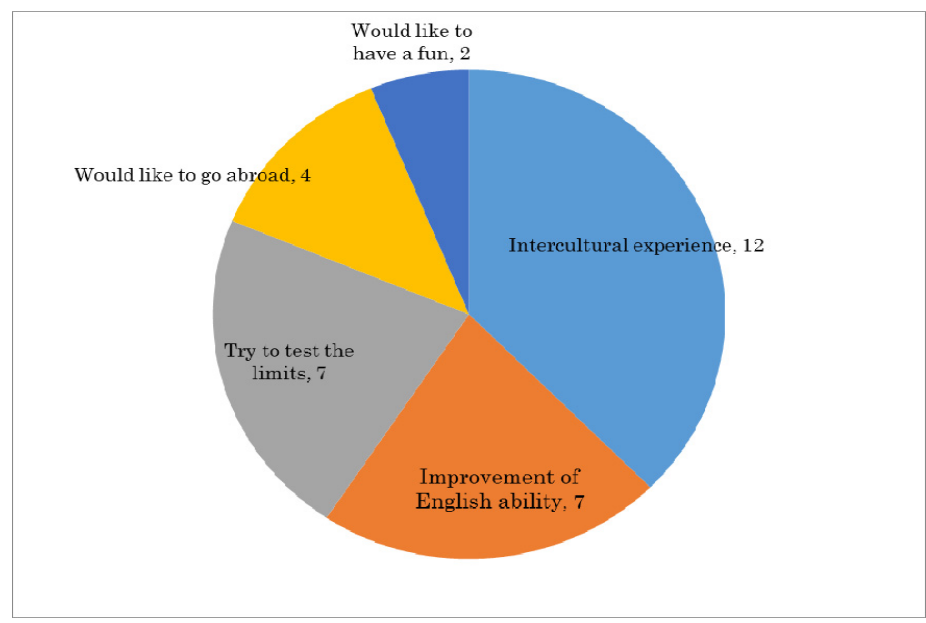

Figure 3. What is your purpose in studying abroad?

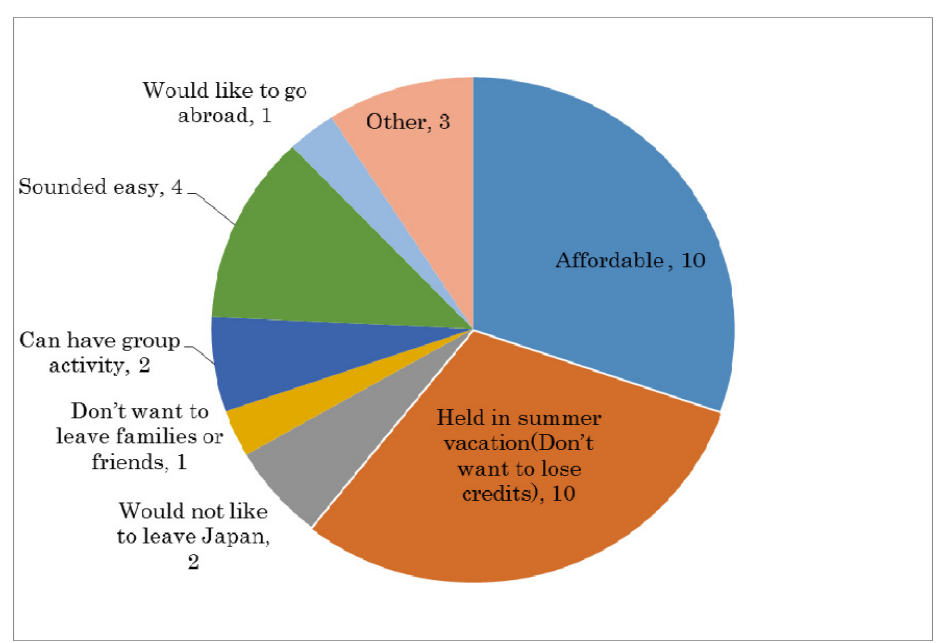

Figure 4. Why did you choose the short-term stay? 


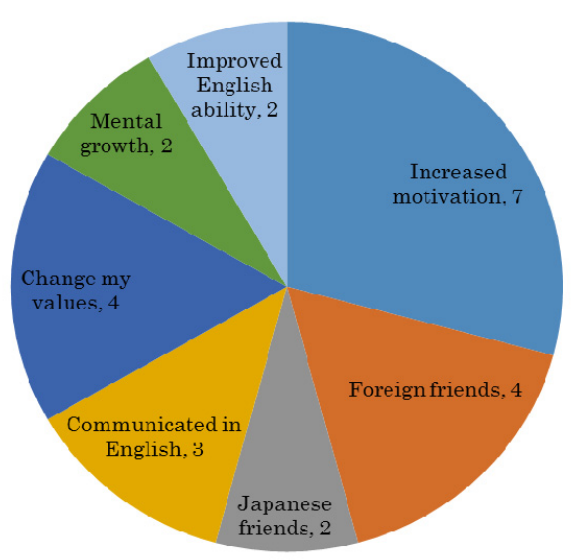

Figure 5. What did you get through studying abroad?

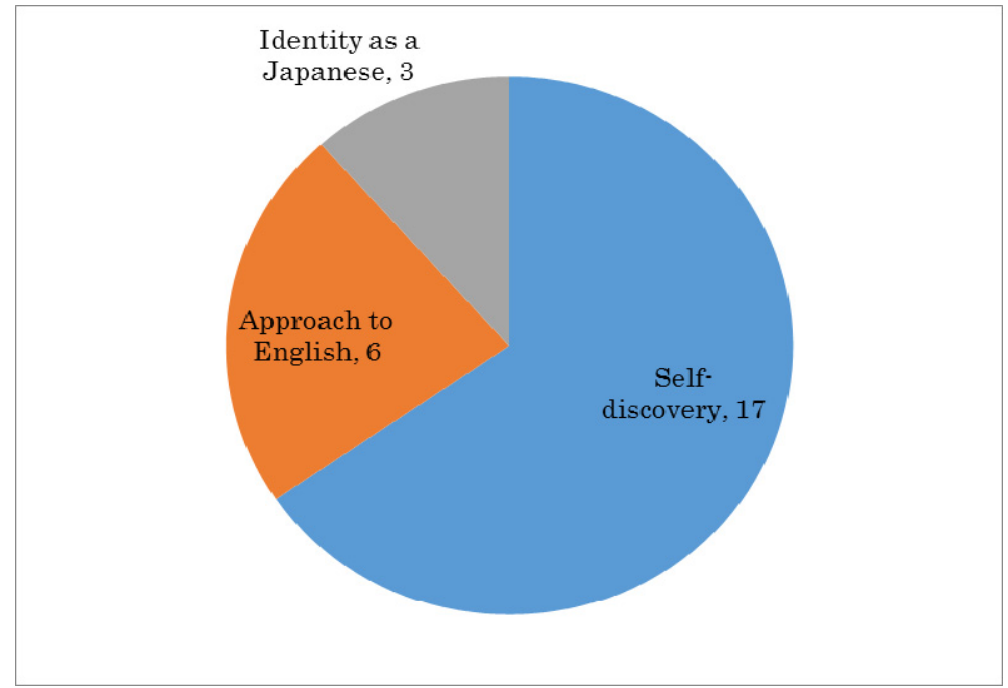

Figure 6. How did you change?

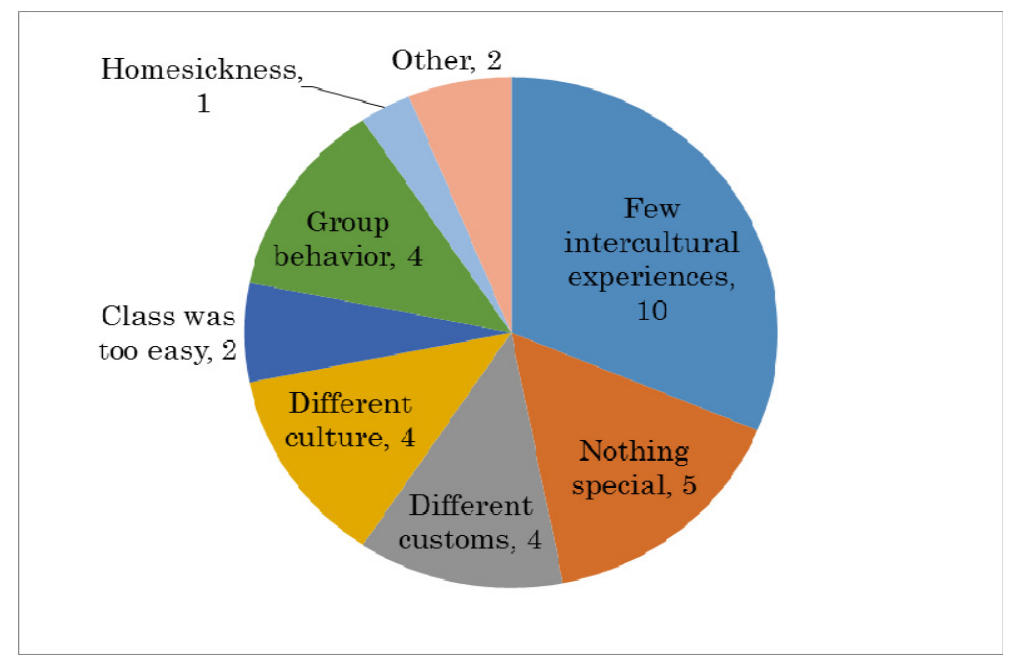

Figure 7. What problems did you experience? 


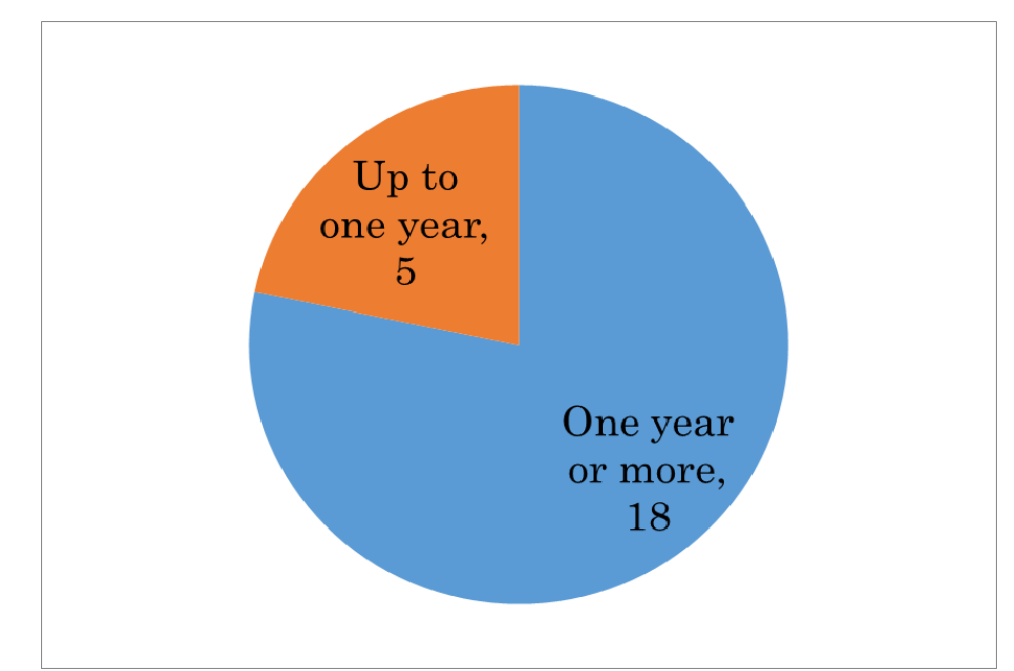

Figure 8 . Which would you prefer next time, short-term or long-term study abroad?

As shown in figure 3, the subjects' main purpose was not study or improvement of English ability but intercultural experience. Some students answered "I'd just like to go abroad" or "I'd just like to have fun", suggesting that the name "study abroad programme" was not appropriate for their goals, for although their period abroad included English language classes, their main purpose was more like personal adventure. It is revealing that although every student who participated in these university-offered programmes received financial support from the university and was told that they would thereby be expected to mentor subsequent study abroad students; no one mentioned the university support or the incurred obligation in interviews.

Figure 4 illustrates the previously-mentioned tendency toward risk avoidance. The 10 students who answered that they chose the short-term programme because it was held in the summer holidays indicated that they wanted to avoid any chance of missing out on course credits, as might happen if they were overseas during term time. Other replies indicating a preference for group activities with Japanese classmates, or for an "easy" option, also suggest risk avoidance. Indeed, Kudo (2009) named this generation "hakoiri" (sheltered) students, and this tendency is reflected and codified by a university directive to students studying abroad — written when the US was essentially the only destination, but still valid today and part of university preparation for participation in study abroad schemes - to the effect that while overseas, students ought to always act in groups for safety.

Figures 5, 6, and 8 illustrate interviewees' changes in soft skills. Few students thought their English ability improved (an impression borne out by the pre-and post-test proficiency tests), but many of them noted that their motivation to study had become stronger, not only for English but also for other subjects such as history or sociology. Others mentioned mental growth, changing values, or self-discovery. Some said that they become aware of their Japanese identity, something they had not previously thought of; or that now when they watch world news, they do so with a wider and more international perspective than their previous Japan-only view (responses labelled as "Identity as a Japanese" and "Self-discovery" in Figure 6, and also "Change my values" in Figure 5). Finally, after their experience, many students gained the confidence to go abroad for a longer period, noting for example that they started off afraid of homesickness or nervous about being apart from their 
families or outside Japan, but after a few weeks overseas felt confident that even a year overseas would be a good experience (see Figure 8). Overall, students often do not clearly identify or quantify the changes and growth they gained through their study aboard, but they are nonetheless convinced that the experience was valuable and they thereby gained some useful skill or ability.

\section{Discussion}

The findings above confirm that short-term Japanese mobile students are not focussed primarily on gaining English proficiency. With "intercultural experience" more important than language skills, and each of testing personal limits and just wanting the experience ranking roughly equal with language skills (see Figure 3), purposes have arguably changed not only from the early one-way absorption of information, but also from the post-1940s two-way exchange, to a more individual and experiential goal.

During the semi-structured interviews students were free to talk freely about their impressions, and some took the opportunity to complain about programmes or recipient institutions. In contrast, others were satisfied with their experiences and took the opportunity to praise the programme or institution (even though neither group of students showed significant improvement in hard skills).

Interestingly, most of the students who were satisfied with their experiences participated in the NZ programme, and the critical feature mentioned repeatedly was that a consultation with staff was scheduled for each student a week after their arrival. Students noted that this system helped them to feel comfortable in a different environment, to focus on their classes rather than stressing over issues with the programme, and to make clear their problems or abilities; even if all problems were not thereby resolved, the process of consultation was seen as making a huge difference. Although other features of the NZ programme may well have also contributed to the high satisfaction level, this consultation seems to have made a substantial impression.

Similarly, an unexpected theme that emerged in interviews was that participating in the interviews- the process of thinking and talking about the experience of studying abroad and what effects it had, some time after the experience itself was concluded - was itself helpful and tended to recast the experience as more important and positive. Students who at first struggled to articulate what they thought they had gained by studying abroad apparently found the process to involve some useful self-discovery, recognizing the meaning of their own experiences by talking about them.

Given these two points - the positive effects of consultation between student and staff while on the programme, and the positive effects of debriefing after their trip - it seems that in order to offer an effective and satisfying programme to the current generation of "sheltered" Japanese mobile students, who often lack clear aims in studying abroad, one useful strategy is to offer consultation and interviews, thereby providing guidance and encouraging self-reflection and involvement.

With this suggestion in mind, it is suggested further than evaluating programmes for Japanese mobile students needs to involve an evaluation of not only soft skill and hard skill changes and how the programme directly meets the needs and expectations of individual participants (termed "micro-viewpoint" below), but also the wider system of support (of preparation, consultation, de-briefing, etc., termed "macro-viewpoint" below) in which the programme is embedded. Figure 9 describes those relevancies. 


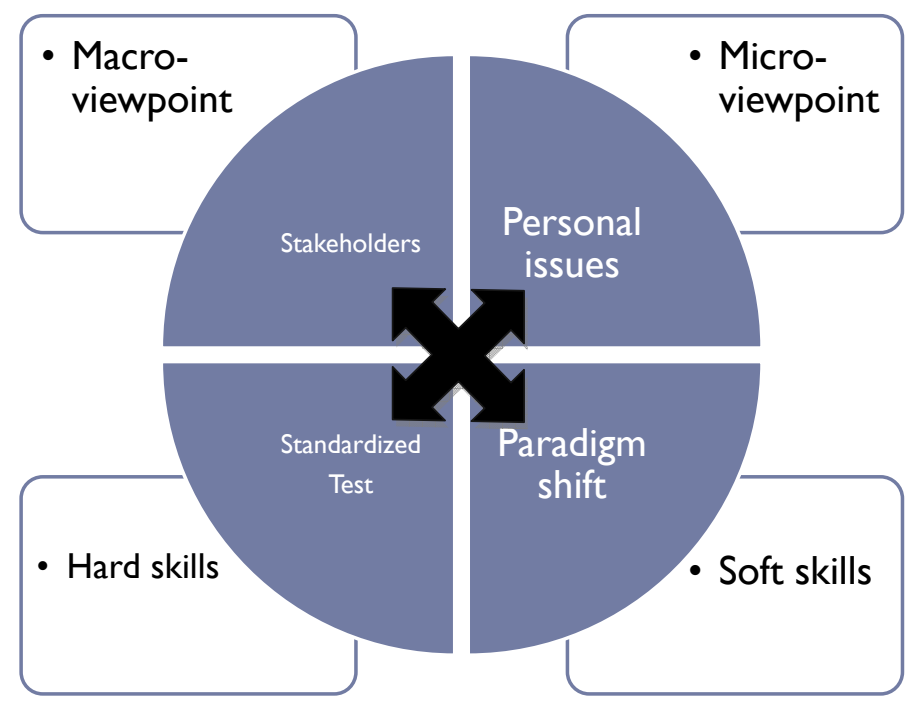

Figure 9. Suggestion regarding how to evaluate programmes.

\section{Conclusion}

In recent years, study abroad has become a more ordinary and personal event (in the sense of being primarily about personal experience, rather than the performance of some national duty). Short-term study abroad episodes themselves have no statistically significant effect on English proficiency, but participants report positive changes and improvements in a range of soft skills, including global and cultural awareness, greater confidence, interpersonal and intercultural communication skills, or some kind of paradigm shift in their way of thinking. Participants themselves often struggle to articulate or understand the meaning or value of these experiences, but guidance before, during, and after trips seems likely to raise the value of those experiences for participants.

\section{References}

Benesse Educational Research and Development Institute. (2013, September 4). Kaigai ryugaku (Study abroad) (Research report, Chapter 3, pp. 53-61). Retrieved from http://berd.benesse.jp/berd/center/open/report/dai_databook/2012/pdf/data_06.pdf

Central Council of Education. (2016, August 24). The report of the promotion of the international exchange about education, the arts and science, the culture, 11 (1956, July). Retrieved from http://www.mext.go.jp/b_menu/shingi/chuuou/toushin/560701.htm

de Wit, H., Ferencz, I., \& Rumbley, E. L. (2014). International student mobility European and US perspectives. Perspectives Police and Practice in Higher Education, 17(1), 17-23.

Edwards, N. T. (2009). The correlation between learner autonomy and cultural sensitivity in Japanese university students studying abroad (Doctoral dissertation, University of Phoenix).

Gondo, Y. (1991). Sekaino ryungaku gennjou to kadai (Comparative perspectives on the study abroad). Tokyo: Toshinsya.

JASSO (Japan Student Services Organization). (2014, September 22). Benefits of study abroad experience: Results from additional survey and analysis for Japanese students supported by the student exchange support program (scholarships for short-term visit program/short-term study abroad program) in 2011 and 2012. Web magazine Ryugaku kouryu (Web magazine studying abroad and exchange), 40(7), 20-30. Retrieved from http://www. jasso.go.Jp/about/documents/201407nomizunitta.pdf

Kaneko, M. (2000). Syuuenn no daigakusei to sono mirai-koutoukyouiku no gurobaruka (University students of the fringe and their future-globalization of higher education). Kyouiku syakaigaku kennkyu, 66, 44-56.

Kimura, K. (2011). How effective the short-term studying program in an English-speaking country is for Japanese university studies: 
Focusing on the listening and writing proficiency. Journal of Shobi University Policy Management, 21, 17-30.

Kudo, K. (2009). Educational impacts of a short-term overseas language programme on university students: A study based upon a grounded theory approach. Speech Communication Education, 22, 117-139.

MEXT (Ministry of Education, Culture, Sports, Science and Technology) Japan. (2015, March 19). Current situation of Japanese studying abroad: Researched by MEXT in 2014 and 2015. Retrieved from http://www.mext.go.jp/_menu/koutou/ryugaku/1345878.htm

Nishikawa, M. (2013). The effectiveness of a preparatory English course and study-abroad programs on improving students' communicative skills: Based on the analysis of a pre-departure IELTS. Journal of Organization for the Promotion of the International Relations (Kyoto University), 3, 61-72.

Tsuji, N. (2010). Kindai nihon kaigai Ryugaku no mokuteki henyou-monbusyou ryungakusei no haken jittai ni tuite (The transformation of the purpose of recent Japanese study abroad). Tokyo: Toshindo. 